\title{
Puerilism in the novel, Waiting for the Mahatma
}

\author{
K. Murali \\ CVR College Of Engineering, H\&S Department, Hyderabad, India \\ E-mail id: mahabhi1310@gmail.com
}

\begin{abstract}
Waiting for the Mahatma", is a more distinct novel than that of other novels written by R.K.Narayan. He depicts an Indian culture predominantly, a South Indian village life. His characters are alive through his description; his settings are vibrant and are reproduced in his pictorial descriptions. The research paper studies how R.K.Narayan depicted the protagonist's character in this novel. In several situations in the novel the protagonist, Sriram behaves like an infant. The infantile behaviour in adulthood is called Puerilism. In this paper a few situations have been taken and analysed to reveal Sriram's character which depicts puerilistic behaviour. This is judged based on the observation of cultural and sociological impact upon a person. We study how family and cultural circumstances impact Sriram.
\end{abstract}

Key words: Distinct, Depict, Predominantly, Puerilism, Vibrant

\section{AIMS AND OBJECTIVES OF THE RESEARCH} PAPER:

1. The aim of the research paper is to demonstrate how the protagonist's character has been portrayed by R.K.Narayan in puerilistic way.

2. Some people in the society behave like children even in adulthood because of their background.

3. A term in psychology Puerilism has been chosen as a key word because it means infantile behaviour in adulthood and the term has been applied to Sriram's character.

\section{INTRODUCTION}

Puerilism is the attitude of a person whose behaviour is juvenile in adulthood. It is based on the influence of apparent cultural and sociological facts. We shall not connect any psychological implications to it. If possible, everyone would behave in calm, rational, balanced manner in different situations. But unfortunately, some people just never grow up completely. If they have to deal with people, they don't keep their sanity. Some people are attention junkies who want all eyes and ears focused on them. Some people are always whining about something. Some people are totally dependent on family members for decision making.

Sometimes adults argue about the things that they are passionate about. This can result in their reminiscences about how they were thinking during their childhood. It can bring out an aspect of such person that is immature, since they want to appear to be correct and want to "win" every argument. People sometimes argue with others because they feel, they have to prove their point. They want that kind of approval and respect, and they think, they will earn it by arguing until they get their way.

\section{REASONS For PUERILISTIC BEHAVIOUR}

Most adults build up all their anger, opinions and stress because they consider that they require it. They don't share their problems often and as obstinate as they are, they often think that they don't need to give evidence for anything. A lot of parents have "do as I say" instead of "do as I do" attitude. They expect their children to jump through hoops without any question simply because he is their child. If not, they throw childish fits because they are afraid of losing control. A lot of adults don't appear to comprehend how they do something though and often don't want to listen to either.

Occasionally the squabble isn't really about the trivial things. Sometimes it is about something greater and one or both of the adults don't have healthy ways of resolving conflicts and tensions so they end up fighting like toddlers over little things also. The big things may be hard to talk about. Both have to focus and work on to resolve it.

Undeveloped adults are hardly ever bad, stupid neither lazy, nor are they immature all the time. Immature adult behaviour reflects a lack of mature parenting and other childhood disappointments. The consequences are most apparent in adults' behaviour. The results of immature parenting include adults who act childishly, driven by obnoxious emotions, obsessions, compulsions and fixations. They may incessantly repeat whatever they did as children to get some alternative for parental love.

Their childlike behaviour may prevent them from considering how their behaviour affects other people. Immature adults frequently observe other people as possible sources for their childish needs, not as human beings who have needs and feelings of their own. Things become more complicated if one ignores the actual age of a person inspite of the childish behaviour and hopes that he will somehow grow up. If one learns to recognize what causes and maintains their childish or teenage behaviour, one can better communicate with them.

Occasionally they can't act like responsible adults. At times they are children mentally and emotionally. One shouldn't be misled by their physical age, education or intelligence - childish people often forget what they have learnt during their childhood. One should try to guess their emotional age. Notice when one acts childishly or feels like a teenager, and gain insight into immaturity. Common triggers for age regression include pain, certain places, certain voices; tricky memories or music that was liked by him as a teenager of their age and background. They may 
express their desires without being. They may have a little idea of who they are although they always know what they need. Not only are they perplexed about who they are, they are perplexed about who you are. And if one allows oneself to become entangled with them, they may be just perplexed.

\section{SOLUTIONS}

On occasions when we know of their childishness; we can treat those people like children. We can give details of their limits, make contingency plans, reward adequate behaviour and describe what is not adequate and the consequences of their violations. Approximately one in every four people might experience an emotional or relationship catastrophe. Perhaps blame may be on economic reasons, on a partner or on some other conflict. Many of these people will seem to shut down, become depressed and express age-regressed emotions. They act childishly and to make childish threats.

Nevertheless, immature people who want to feel good without effort may resent any hints that their behaviour is at fault. One shouldn't expect to be showered in appreciation if they mention that their mental status is late for a wash. Childhood disturbance can lead to an incapability to make adult decisions; with coupled associated embarrassment, guilt and self-abuse, as well as limiting beliefs, learning disabilities, depression and relationship disorder. We can help them locate and incorporate their childish parts as steps on their trail to emotional maturity and adult relationships.

\section{A FeW Situations In The Novel Which ReVeal SRIRAM's PUerilistic Behaviour}

The protagonist, Sriram's character has been depicted in a puerilistic way. His mother died immediately after he was born and his father was killed in Mesopotamian war. He was brought up by his grandmother. When postman brings oblong cover on the first day of every month, addressed to his grandmother, she weeps on seeing it; his infantile behaviour makes him wonder. When he was about one year old, his grandmother used to show the traffic passing outside, making him sit on the cold cement window-sill. Thus sitting on window-sill becomes a habit for him. When he grows up, he seeks no other place except the window-sill. His grandmother reproaches him for not mingling with the others of his age, he replies that he feels happy being alone. Thus he becomes an introvert and adapts to only that kind of environment. He behaves like a child in several situations in the novel.

On the twentieth birth day of Sriram, his grandmother decorates the house with mango leaves and she brings sugar-cane, as she feels bringing sugar-cane is very auspicious. She wants to call neighbours to celebrate his birthday grandly, but her solitary grandson prohibits her from inviting anyone. She has been planning to celebrate his twentieth birthday, engaging pipes and drums and processions for the particular birthday to hand over the savings pass book to him and give up the trust. All her plans have become futile because of his behaviour. When she takes him to the bank to open an independent account, the neighbours call him an urchin, she shouts at them, saying he is not an urchin and says he is old enough to take charge of his own affairs.

In one instance in the novel, Sriram meets a young lady, Bharathi who is a follower of Gandhiji at their camp. She is very talkative and sharp-tongued girl. He wants to be a volunteer of Gandhiji's camp for being in her company. He feels that Bharathi is a very good match for him. When he keeps on asking questions to infatuate her, she gets irritated. She doesn't answer him properly. He uses malapropisms while answering; she easily notices that he has turned up for her. After knowing that he is a parentless man who is brought up by his grandmother, she becomes tender and speaks to him kindly. After the conversation he realises that it is difficult to please her and knows that she is a termagant. He gets to know that she is a parentless girl like him. He convinces her saying he has something to do without wasting time in life. He pleads with her to allow him as one of Gandhiji's disciples. She asks him what he would tell his grandmother. Then he mumbles and makes some indistinct sounds. He also asks her what he has to do. On hearing this she feels that she is superior to him in intelligence and questions why she should talk to him. He says that he likes her and wants to be with her. Then she bursts into laughter and says, "That won't be sufficient". If you speak like that, they may chase you away. He becomes sullen and gloomy. She enjoys teasing him. Now he really wants to do something and tells her not to make fun of him. She asks him whether he would be willing to meet her. He replies that he is not interested in meeting and tells her that he doesn't know how to behave with her. She becomes very serious with him and commands that he must face Gandhiji if he really wants to work with him. Then he loses his temper and cries at Bharathi that he would meet her anywhere except before Gandhiji. He doesn't want to become a fool before Gandhiji. Bharathi replies finally if he wishes to meet her, the only place he could meet her was before Gandhiji. If he doesn't want to meet her there, he can leave her. Sriram agrees to meet her there at 3.00am.

Sriram has been given a task of spreading the message of Quit India by writing "Quit India" on far-flung villages of the area. He travels in the forest area where elephants were hauling timber. The timber contractor exports the timber to far off countries for money. He explains the contractor that the British are going to use this timber for the destruction of the world by making ships and rifles. The timber contractor pleads with him not to trouble them and informs that they are just business men. Then Sriram tells him that this is not the time for acquiring money but time to join in the fight for independence. Sriram informs him about Gandhiji's non-violence, but he is not convinced with the message, as he is interested in making money. The contractor treats him like a child. Sriram knows that it is difficult to convince him. He can't understand that he is treated like a child. He decides to leave the contractor and goes to other villages from there. 
In Solur village Sriram has a funny conversation with the shopkeeper. The shop keeper asks where he is from, he replies, "from faraway" and he enquires where he is going and he replies, "Faraway" again. The people at the shop laugh at this. The shopkeeper asks him to have nice biscuits. Sriram asks whether they are from England. Then he replies yes and says that he got them from his friend who is in the army. Sriram scolds him for selling biscuits from England. The shopkeeper calls him a rowdy and ridicules him for the khadi dresses. He is hurt by such comments. Sriram threatens the shopkeeper that he can talk anything about him, but not about the dress, as it is too scared to be spoken in that way. The shop keeper feels intimidated by his manner. Sriram wants to make him understand the importance of the dress and not selling foreign goods. The shop keeper doesn't want the little circle of watchful people who are gathering. But Sriram does not leave him and sits in front of the shop. He there behaves like a child who is sulky with his mother for not giving him money. The people enjoy the scene. He doesn't even allow customers to buy anything in the shop until the shop man throws biscuits into the drain. The shop man apologises and assures him that he won't sell foreign goods again. This pleases Sriram and he leaves from there.

A person, Jagadish comes across Sriram one day and introduces himself as a national worker. He also says that one of his friends met Bharathi in the jail. This makes Sriram happy and enquires about Bharathi. Jagadish easily swindles him saying that he is a follower of Gandhiji's non-violence. Gradually he becomes closer to Jagadish and involves in his violent activities, though he has trepidation. He sets fire to the court records in different places, derails couple of trains and explodes bombs. Sriram once questions Jagadish about violent activities and loss of people's lives. Jagadish convinces him. But he is not sure if this is right or wrong. He recollects Bharathi if she is with him she would have helped. Then the police search for Sriram because of his violent activities. He is arrested by the police, when he saves the grandmother from the pyre. This shows how he is treated as gullible by the other characters in the novel.

\section{CONCLUSIONS}

This research paper studies a few reasons and solutions for puerilistic attitude. The protagonist, Sriram's conversation with his grandmother, Bharathi, the timber contractor, shopkeeper in Solur village, and Jadish has been presented in the paper. Thus the few situations in the novel reveal that Sriram's character has puerilistic attitude because of social and cultural impacts on him.

\section{REFERENCES}

1. Waiting for Mahatma, Indian thought Publications.

2. Psychological terms from Internet. 